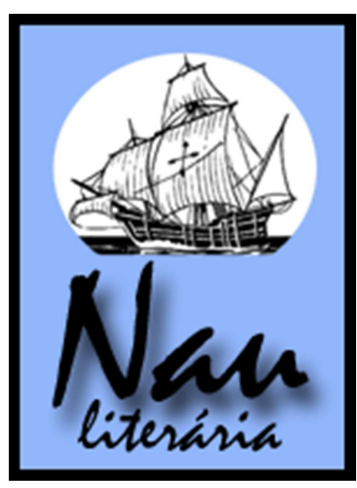

\title{
A análise da ironia da personagem Dom Bibas no romance $O$ Bobo, de Alexandre Herculano
}

\section{Juliana Ferreira Paz}

\begin{abstract}
Resumo: Este artigo tem por objetivo verificar como se ocorre o fenômeno da ironia na personagem Dom Bibas na obra de Alexandre Herculano "O bobo", bem como sua constituição como romance histórico. A partir dessa análise, pretendo verificar como a questão da ironia se apresenta nas falas e na descrição da personagem de Dom Bibas e sua influência na obra em questão.
\end{abstract}

Palavras-Chave: ironia, Herculano, Dom Bibas, romance histórico.

\begin{abstract}
This article aims to verify how the phenomenon of irony in the character Don Bibas in the book of Alexandre Herculano "O bobo" and its establishment as an historical novel. From this analysis, I want to see how the question of irony is presented in the speeches and the description of the character of Don Bibas and its influence on the book in question.
\end{abstract}

Keywords: irony, Herculano, Dom Bibas, historical romance.

O romance histórico de Alexandre Herculano, bem como suas obras que retratam a história real de Portugal como "História e Origem da Inquisição em Portugal" foram de suma importância para a constituição da unicidade e do conceito de nacionalidade de Portugal. Herculano utilizou-se dos princípios básicos da composição do romance histórico descritos na obra de Georg Lukács "La Novela Histórica” para compor uma de suas obras de maior relevo e repercussão em Portugal: "O bobo". Segundo Lukács, o romance histórico tem como fundamento:

\begin{abstract}
Pero en este recorrido no encontrará nada que pudiese aclarar en algo fundamental el fenómeno de la novela histórica. Las llamadas novelas históricas del siglo xvii (Scudéry, Calprenéde, etc.) son históricas sólo por su temática puramente externa, por su apariencia. No sólo la psicología de los personajes, sino también las costumbres descritas responden por completo a la época del novelista. Y la más famosa "novela histórica" del siglo XVIII el Castle of Otranto (Castillo de Otranto), de Walpole, trata igualmente la historia como algo meramente superficial; lo que interesa aquí realmente es la curiosidad y excentricidad del ambiente descrito, no la representación artisticamente fiel de un periodo histórico concreto. (LUKÁCS, 1966, p. 15).
\end{abstract}

Como descrito em Lukács, Herculano utilizou a história da constituição do país português como plano de fundo para desenvolver o romance que havia criado. Enquanto

\footnotetext{
* Graduanda em Letras (UFRGS).
} 
desenvolve uma história de amor no triângulo amoroso entre Dona Dulce, Dom Egas Muniz e Garcia Bermudez, está ocorrendo no cenário histórico português a briga de Dom Afonso Henriques com sua mãe Dona Teresa pela posse do trono, pois Dom Afonso não aceita o casamento da mãe com Fernando Peres, por considerá-lo um usurpador do trono real. No decorrer dessas histórias paralelas, está inserida a personagem principal do romance: Dom Bibas, que nada mais é do que o bobo da corte do castelo de Guimarães, menosprezado por todos, principalmente por Fernando Peres, a quem recusou ser escravo e a quem dirige a maioria de suas graças e piadas. Nessa personagem, Herculano explora um aspecto que traz para a obra algo que a diferencia das demais: o uso da ironia.

A ironia, como figura de linguagem que tem por intenção dizer o contrário do que se afirma para zombar ou caçoar de alguém, faz-se presente também em outras obras de Herculano, conforme escrito por Ann-Marie Mathiassen:

Na obra de Herculano a ironia apresenta-se tanto verbal como situacional/ dramática, aparece isolada na frase e disseminada no texto inteiro, revela-se aberta ou escondida, benévola ou sarcástica. Vou considerar O Pároco de Aldeia e O Monge de Cister no meu estudo da ironia em Herculano. No primeiro, Herculano adopta um estilo humorístico, e a ironia, embora crítica, manifesta-se bondosa e toma muitas vezes um aspecto burlesco. No Monge de Cister, obra polémica e muito mais complexa, também há uma ironia que se aproxima da paródia, mas a ironia aqui, a par de mediar uma visão crítica da sociedade, percebe-se como uma ironia que exprime o conflito. (MATHIASSEN, 2002, p.02)

A partir dessa definição de como procede à questão da ironia nos textos de Herculano, pode-se afirmar que a mesma está presente na obra "O Bobo" de forma situacional, aberta e escondida (em certos pontos) ou dramática (sarcástica). Na cena descrita a seguir, podemos perceber a presença da ironia na forma sarcástica e aberta na fala de Dom Bibas, enquanto ele escutava a conversa entre o Cônego Martin Eicha, Gonçalo Mendes e o abade beneditino:

Dom Bibas pareceria também uma criação desvairada da mente do escultor, se, fitando os olhos brilhantes no reverendo cónego e fazendo-lhe uma visagem truanesca, não começasse a cantarolar com um acompanhamento de risadas estrondosas:

Quem me dera o meu infante

Nestes seus paços reais

Doravante!

Tra-lirá,

Ah, ah, ah!

Ovençais

Do galego

Só i vejo a cada instante!

Arrenego,

Dom Garcia

Desses teus aragoneses,

E também dos portugueses

Que te fazem companhia!

Capelão, Canzarrão,

Ao, ão, ão!

Tra-lirá, 


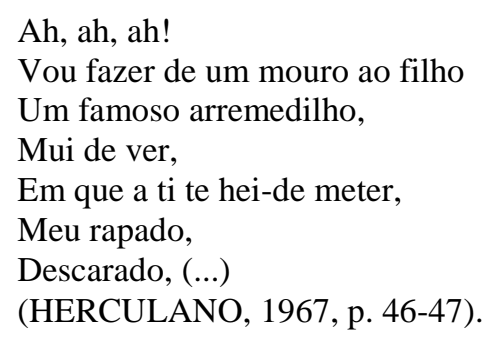

Nesse trecho, podemos perceber que Dom Bibas está falando de forma irônica da personagem do Cônego e do Frei Hilarião ao utilizar-se de palavras como Capelão (que significa, além de padre, macaco velho e esperto) e Canzarrão (que significa cachorro grande) e ao falar do vício da gula da personagem do Frei Hilarião e de como o mesmo engana o Papa, ao passar-se por homem santo.

Em outra cena, o narrador descreve a sátira feita por Dom Bibas a Garcia Bermudez na ocasião do sarau onde estavam a rainha e Fernando Peres:

Dom Bibas, que, repotreado na cadeira da rainha, olhava para ele fito, e lhe salmeava em tom soturno, pela solfa do canto gregoriano, bastas injúrias:

Fora, parvo aragonês.

Dom bulrão.

Tlão, tlão, tlão!

Vai tratar de teus amores

No Aragão.

Tlão, tlão, tlão!

As donzelas portuguesas

Lindas são.

Tlão, tlão, tlão!

E por isso haver quer uma

Dom bulrão.

Tlão, tlão, tlão!

A Dulce é bela donzela;

Mas flor d'aleli

Não é para ti.

Kirieleison.

Kirieleison.

Requiem ceternam dona eis

Et lux luceat eis. (HERCULANO, 1967, p. 48)

Neste trecho, Dom Bibas faz escárnios de Garcia Bermudez ao falar-lhe que ele não merece Dona Dulce por ser um aragonês ao utilizar em seu canto palavras como "aragonês" no sentido pejorativo e "Bulrão" (que provem da palavra bulra que significa que significa "burlar").

Além da fala de Dom Bibas, a ironia também está presente em vários aspectos narrados na história relacionados à personagem como na seguinte passagem:

E não era lá nenhum grande homem: era um vulto de poucomais de quatro pés de altura; feio como um judeu; barrigudo como um cónego de Toledo; imundo como a consciência do célebre arce-bispo Gelmires, e insolente como um vilão de beetria. Chamava-se de seu nome Dom Bibas. (HERCULANO, 1967, p.23) 
Essa descrição de Dom Bibas acaba por criar uma ironia quanto ao epílogo do livro, pois ao ajudar Don Afonso Henriques a derrotar Dom Fernando Peres, ele acaba se tornando um herói que ajudou a consolidar a história de Portugal. Podemos perceber a importância de Bibas no trecho a seguir:

É o que não nos diz a história. Pouco importa: di-lo-emos nós. A história não conheceu Dom Bibas, e Dom Bibas, muito em segredo o revelamos aqui aos leitores, nos oferece a chave deste mistério. O bobo tornara impossível semelhante arbítrio, e porventura ajudara a descer do céu a bênção que cobriu as armas de Afonso Henriques. (HERCULANO, 1967, p.167)

No decorrer dessa narrativa, a ironia está presente em todos os aspectos, desde a composição física da personagem Dom Bibas, na constituição de seu caráter e em suas falas. Esse caráter satírico que compõe a essência da personagem Dom Bibas é o que traz para a obra uma valorização única, tornando-a tão famosa entre os portugueses até hoje.

Enfim, ao utilizar a ironia como um recurso de linguagem no desenvolvimento de sua obra, Herculano agregou a ela um valor estético especial ao operar nas contradições da realidade, nas ambiguidades e nas sátiras dos fidalgos, da história e dos costumes da corte de Portugal. Como ressalta Mathiassen:

Apesar de não conseguir libertar-se de um tom retórico e moralizante, a ironia em Herculano e em outros românticos portugueses, na sua perspectiva alargada quanto ao processo criador, inicia uma evolução da concepção da ironia que na metaliteratura moderna do seu país acaba por constituir um elemento de estrutura fundamental. (MATHIASSEN, 2002, p. 1027).

Ao inserir a ironia como um componente fundamental na obra "O bobo", Herculano não só se consolidou como um grande romancista português, como serviu (e serve) de inspiração para obras de diversos autores portugueses. Herculano, ao utilizar-se de ironia na composição da personagem Dom Bibas, conseguiu não só fazer uma crítica à história e à cultura da época, mas também criar uma personagem que marcou a história portuguesa, mesmo sendo fictícia.

\section{Referências}

HERCULANO, Alexandre. O bobo. São Paulo: Difusão Europeia do Livro, 1967.

LUKÁCS, Georg. La novela histórica. Cidade do México: Ediciones Era, 1966.

MATHIASSEN, Ann Marie. A ironia romântica na obra novelística de Alexandre Herculano. Oslo: Universitetet i Oslo, 2002. 